\section{Visual acuity in children with autism spectrum disorder}

\author{
Omar García Liévanos, ${ }^{1}$ \\ Amalia G. Gómez Cotero, \\ Edith López Suárez, ${ }^{2}$ \\ Ana Karen Melgoza Galván² \\ ${ }^{1}$ Interdisciplinary Center for Health \\ sciences Unit Milpa Alta (IPN); \\ ${ }^{2}$ Interdisciplinary Center for Health \\ sciences Unit Saint Tomas (IPN), México \\ City, México
}

\begin{abstract}
Today, controversy still surrounds the acuity visual (VA) in adolescents and adults with autism spectrum disorder (ASD). ASD has been associated with hypersensitivity but recent studies have questioned these results. The aim of this study was to compare VA in children with ASD and typically developing children (TD). The study included 34 children: 12 with ASD [people living with (PW) ASD group: 1 female, 11 males] and 22 TD (PWTD group: 9 females, 13 males). The PWASD group was from the Clinica Mexicana de Autismo (CLIMA) and the PWTD group was from the Aztecas elementary school. VA was measured with Kay picture test cards for children without correction. Right eye VA of the PWASD group ranged from 0.2 to $1.0(0.88 \pm 0.23)$ and left eye VA ranged from 0.2 to $1.0(0.87 \pm 0.23)$. Right eye VA of the PWTD group ranged from 0.3 and $1.0(0.84 \pm 0.23)$ and left eye VA ranged 0.3 and $1.0(0.78 \pm 0.22)$. Non-statistically significant differences were found (t-test, $\mathrm{P}>0.05$ ). Results support the view that visual acuity is not affected in children with ASD compared with TD children.
\end{abstract}

\section{Introduction}

The term autism comes from the word autos meaning self. Even though autism had already been recognized, it was only in 1943 that Leo Kanner first described autistic behavior in detail. Before Kanner, this type of behavior was generally known as child schizophrenia. Autism etiology remains an enigma for scientists. The most probable hypothesis is a central nervous system dysfunction. As far as vision is concerned, autists tend to have abnormal electrorretinograms, deficient visual-evoked potentials, and atypical optokinetic nystagmus. They also experience a higher occurrence than expected of strabismus, oculomotor deficiencies and refraction. ${ }^{1}$ Autism appears to be a severe form of personality disorder affecting communication, imagination, planning and emotional reciprocity.

According to a 1996 study in the United States and metropolitan areas, the prevalence of autism was 3-4 for each 1000 children. $^{2}$ Between 1987 and 1998, there was a 273\% increase in autism observed in the population of California, USA, according to the development services department report. This increase is due partly to a greater awareness on the part of all members of the community.

In 1975, Streff published the first publications mentioning the main optometric signs in autism, including normal binocular vision and defects in ocular motility. He also reported great limitations in visual contact and spatial relationships at relatively short distances. ${ }^{3}$

In 1977, Newsom and Simon studied nonverbal autistic children by means of an ordered simultaneous discrimination procedure to measure acuity visual (VA); 2 of these children were identified with important loss of VA. ${ }^{4}$

In 1989, the association between autism and Leber's congenital amaurosis (LCA) was investigated. It was found that both produce neurological damage but greater damage was found in LCA. ${ }^{5}$

In 1992, a study by Scharre evaluated vision dysfunctions such as ocular motility, VA and stereopsis in patients with autism and concluded that they did not present ocular diseases. Nevertheless, they found alterations in refractive errors and strabismus. ${ }^{6}$

In 1997, the pediatric department of ophthalmology at the Timamane hospital, Marseille, carried out a study on autistic children and found a large number of unilateral, bilateral astigmatisms and binocular vision problems. $^{7}$

In 2002, Van der Geest Camfferman observed the relationship between the abnormal physical appearance of autistic children and their information processing; although they did not identify a clear relationship due to the inaccurate analytical methods used. ${ }^{8}$

In 2003 , a study was conducted into visual attention in 2-year old autistic children. This study concluded that these children demonstrated ocular perception although there might be no ocular movement or the children did not follow the gaze of others. ${ }^{9}$

In 2007, two studies reported that some children with congenital blindness presented autistic behavior, depending on their etiology, genetics and pathology. However, this association is not very clear. ${ }^{10,11}$

Also in 2007, an investigation was carried out into speech audiovisual integration deficit and lip-reading in individuals with autism, how this may contribute to difficulties of speech, and its possible relationship with retarded early speech development. ${ }^{12}$

In 2008, a study determined that people with
Correspondence: Omar García Liévanos, Interdisciplinary Center for Health sciences Unit Milpa Alta (IPN), Ex-Hacienda del Mayorazgo, Km. 39.5 Carr. Xochimilco-Oaxtepec, C.P. 12000 A.P. 5, México City, México.

Tel. +1.55.57296000 Ext. 82339. E-mail: ogarcial@ipn.mx; amaliagpegomez@prodigy.net.mx

Key words: acuity visual, autism spectrum disorder, sensorial integration.

Contributions: 0GL, optometry coordinator; AGGC, psychology coordinator; ELS, AKMG optometry students.

Received for publication: 9 May 2012.

Revision received: 21 August 2012.

Accepted for publication: 12 September 2012.

This work is licensed under a Creative Commons Attribution NonCommercial 3.0 License (CC BYNC 3.0).

(C) Copyright O.G. Liévanos et al., 2012

Licensee PAGEPress, Italy

Optometry Reports 2012; 2:e5

doi:10.4081/optometry.2012.e5

autism tend to have abnormal electroretinograms, deficient evoked visual potentials, and atypical opticokinetic nystagmus, besides a higher than expected incidence of strabismus and oculomotor deficiencies, refractive and binocular vision status. ${ }^{13}$

In 2009 , a study was conducted using a psychophysical test of visual sensibility to human movement in relation to object movement in ASD. It found a higher visual sensibility to human movement, but suggested that ASD cannot adjust social visual information. ${ }^{14}$

Koh, Milne and Dobkins studied contrast sensitivity to 7 spatial frequencies obtaining measurements for 4 parameters; one of these was VA and it was inferred that there was no difference between autism spectrum disorder (ASD) individuals and controls for any of the 4 parameters measured. However, there was no evidence to support such a hypothesis. ${ }^{15}$

Franklin et al. conducted a study on ASD and color perception using the FrannsworthMunsell Test with 100 test hues and found there was a general reduction in chromatic sensitivity. They concluded that there was a relationship with cortical models of perspective processing. ${ }^{16}$

Milne et al. studied many vision aspects, including VA. On average they reported significantly poorer results in both eyes in the ASD group compared with the typically developing group. However, data suggest that many aspects of vision, including VA, are unaffected in ASD. ${ }^{17}$

Sven et al. ${ }^{18}$ found that people living with 
(PW) ASD did not have higher VA than either patients with schizophrenia or typically developing subjects. Tavassoli et al..$^{19}$ analyzed the VA in adults with ASD and adult controls and found no significant differences between groups.

Nevertheless, Ashwin et al..$^{20}$ analyzed VA in patients with autism spectrum disorder using Freiburg's VA and contrast test. Results showed that PWASD have a significantly better VA (20/7) than those not having this disorder (20/13), and Mark et al. ${ }^{21}$ also find a better VA in PWASD (20/13) than controls (20/21).

\section{Materials and Methods}

The present study group included 34 children: 12 with ASD (PWASD group: 1 female, 11 males) and 22 with typically developing children (TD) (PWTD group: 9 females, 13 males). The ASD group is from the Clinica Mexicana de Autismo (CLIMA) and the TD group is from the Aztecas elementary school. Selection for the TD group was made by simple random sampling. The CLIMA and Aztecas elementary school are localized in a metropolitan area of Mexico City. All patients from the CLIMA had been diagnosed with ASD by psychologists. The VA was evaluated with Kay picture test cards without correction. The test cards were presented to the patient at a distance of $3 \mathrm{~m}$. The patient did not have any distractions (colors, figures, persons not concerned with the test) while the test was being carried out. Only the child's therapist and optometrist were present during VA testing. All procedures were conducted according to the Declaration of Helsinki. We used SPSS 17 software for statistical analysis with independent sample MannWhitney test, related sample Wilcoxon's signed ranks test, paired sample t-test and linear regression models.

\section{Results}

Twelve children from the CLIMA (age range 6 - 12 years, mean $8 \pm 2.68$ ) and 22 children from the Aztecas elementary school (age range 6-11 years, mean $8.36 \pm 1.53$ ) were studied. Figure 1 shows frequency distribution in years.

Kolmogorov-Smirnov (K-S) test showed that VA values for right and left eyes in the PWTD group $(\mathrm{P}=0.002$ and $\mathrm{P}=0.046$, respectively) and VA values for right and left eyes in the total sample $(\mathrm{P}=0.00008$ and $\mathrm{P}=0.005$, respectively) were not normally distributed and thus no parametric tests were used. K-S test showed that VA values for right and left eyes in the PWASD group $(\mathrm{P}=0.092$ and $\mathrm{P}=0.220$ respectively) were normally distrib- uted and parametric tests were used (Figure 1). VA of the PWASD group in the right eye ranged from 0.2 to $1.0(0.88 \pm 0.23)$ and from 0.2 to $1.0(0.87 \pm 0.23)$ in the left eye. Paired sample t-test showed no significant difference in VA between right and left eyes $(\mathrm{t}=0.561$; $\mathrm{P}=0.586$ ).

VA of PWTD in the right eye ranged from 0.33 to $1.0(0.84 \pm 0.23)$ and from 0.33 to 1.0 $(0.78 \pm 0.22)$ in the left eye. Related sample Wilcoxon's test showed a slightly significant difference in VA between right and left eyes ( $\mathrm{z}=-1.833$; two-tailed $\mathrm{P}=0.067$ ).

Independent sample Mann-Whitney test found no significant difference in VA of the right eye between the PWASD and the PWTD groups $(\mathrm{z}=-0.507$; two-tailed $\mathrm{P}=0.612)$ and no significant difference in the left eye between groups $(\mathrm{z}=-1.364$; two-tailed $\mathrm{P}=0.173)$.

PWTD

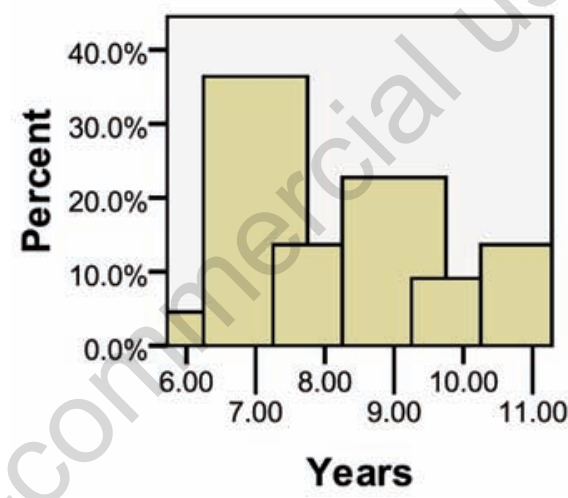

Figure 1. Age distribution in years. PW, people living with; TD, typically developing children; ASD, autism spectrum disorder.

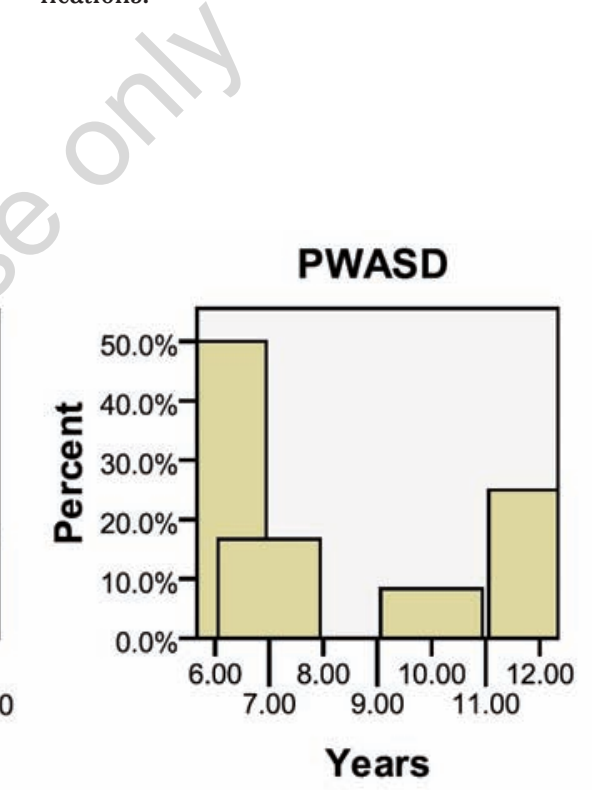

\section{Discussion}

Bölte et al. ${ }^{18}$ and Tavassoli et al. ${ }^{19}$ reported no significant differences between adolescent and adult controls and adolescents and adults with ASD. Milne et al. ${ }^{17}$ reported that many vision aspects, including VA, are not affected in autism spectrum disorder in children. Our findings in children support their results.

Ashwin et al..$^{20}$ and Brosnan et al. ${ }^{21}$ studied VA in 13 adolescent and adult males with ASD and compared their results with those of 13 adolescent and adult male controls. VA in the ASD group was better (2.85 decimals, 20/7) than controls (1.55 decimals, 20/13). The differences between these and our results depend upon the method and the distance used to measure the VA, and age and diagnostic classifications. 
The main limitation of our study is that, in the PWTD group, we did not use a questionnaire about the history of developmental or neuropsychiatric disorder, nor did we have data relating to the diagnostic classifications of ASD. Also, this study is limited by a small sample size, and further studies with more patients and including a full clinical case-history analysis are required.

\section{Conclusions}

The data suggest that there is no significant difference in VA between children with ASD and TD children for right and left eyes. Our results support the view that VA is not affected in children with ASD.

\section{References}

1. Waintraub JS. Background and history of autism in relation to vision care. $\mathrm{J} \mathrm{Am}$ Optom Assoc 2008;79:560-1.

2. Yeargin-Allsopp M, Rice C, Karapurkar T, et al. Prevalence of Autism in a US Metropolitan area. JAMA 2003;289:49-55.

3. Streff JW. Optometric care for a child manifesting qualities of autism. J Am Optom Assoc 1975;46:592-7.

4. Newsom CD, Simon KM. A simultaneous discrimination procedure for the measurement of vision in nonverbal children. $\mathrm{J}$
Appl Behav Anal 1977;10:633-44.

5. Rogers SJ, Newhart-Larson S. Characteristics of infantile autism in five children with Leber's congenital amaurosis. Dev Med Child Neurol 1985;31:598608.

6. Scharre JE, Creedon MP. Assessment of visual function in autistic children. Optom Vision Sci 1992;69:433-9.

7. Denis D, Burillon C, Livet MO, Burguière 0. Ophthalmologic signs in children with autism. J Fr Ophtalmol 1997;20:103-10.

8. Van der Geest JN, Kemner C, Camfferman G, Verbaten MN. Looking at images with human figures: comparison between autistic and normal children. J Autism Dev Disord 2002;32:69-75.

9. Chawarska K, Klin A, Volkmar F. Automatic attention cueing through eye movement in 2-year-old children with autism. Child Dev 2003;74:1108-22.

10. Mukaddes NM, Kilincaslan A, Kucukyazici G, Sevketoglu T. Autism in visually impaired individuals. Psychiatry Clin Neuros 2007;61:39-44.

11. Allison CL, Gabriel H, Schlange D, Fredrickson S. An optometric approach to patients with sensory integration dysfunction. Optometry 2007;78:644-51.

12. Fazz IE, Rossi M, Signorini S, et al. Leber's congenital amaurosis: is there an autistic component? Dev Med Child Neurol 2007;49:503-7.

13. Trachtman JN. Background and history of autism in relation to vision care. Optometry 2008;79:391-6.
14. Kaiser MD, Delmolino L, Tanaka JW, Shiffrar M. Comparison of visual sensitivity to human and object motion in autism spectrum disorder. Autism Res 2010;3:1915.

15. Koh HC, Milne E, Dobkins K. Spatial contrast sensitivity in adolescents with autism spectrum disorders. J Autism Dev Disord 2010;40:978-87.

16. Franklin A, Sowden P, Notman L, GonzalezDixon M. Reduced chromatic discrimination in children with autism spectrum disorders. Develop Sci 2010;13:188-200.

17. Milne E, Griffiths H, Buckley D, Scope A. Vision in children and adolescents with autistic spectrum disorder: evidence for reduced convergence. J Autism Dev Disord 2009;39:965-75.

18. Bölte S, Schlitt S, Gapp V, et al. A Close eye on the eagle-eyed visual acuity hypothesis of autism. J Autism Dev Disord 2011;42: 726-33.

19. Tavassoli T, Lathamb K, Bach M, et al. Psychophysical measures of visual acuity in autism spectrum conditions. Vision Res 2011;51:1778-80.

20. Ashwin E, Ashwin C, Rhydderch D, Howells J. Eagle-eyed visual acuity: an experimental investigation of enhanced perception in autism. Biol Psychiatry 2009;65:17-21.

21. Brosnan MJ, Gwilliam LR, Walker I. Brief report: the relationship between visual acuity, the embedded figures test and systemizing in autism spectrum disorders. $\mathrm{J}$ Autism Dev Disord 2012:1-7. 